\title{
Improving pancreatic islet in vitro functionality and transplantation efficiency by using heparin mimetic peptide nanofiber gels
}

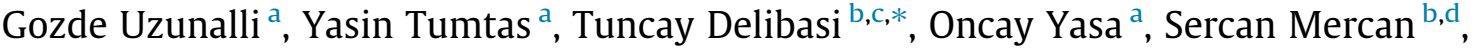 \\ Mustafa O. Guler ${ }^{\mathrm{a}, *}$, Ayse B. Tekinay ${ }^{\mathrm{a}, *}$ \\ a Institute of Materials Science and Nanotechnology, National Nanotechnology Research Center (UNAM), Bilkent University, Ankara 06800, Turkey \\ ${ }^{\mathrm{b}}$ Pancreas Islet Cell Research Center, Ankara Diskapi Yildirim Beyazit Training and Research Hospital Etlik Polyclinic, Department of Endocrinology and Metabolism, Ankara \\ 06800, Turkey \\ ${ }^{\mathrm{c}}$ Hacettepe University, School of Medicine, Department of Endocrinology, Ankara 06100, Turkey \\ ${ }^{\mathrm{d}}$ Gazi University, Faculty of Science, Department of Chemistry, Ankara 06560, Turkey
}

\section{A R T I C L E I N F O}

\section{Article history:}

Received 18 December 2014

Received in revised form 17 April 2015

Accepted 21 April 2015

Available online 27 April 2015

\section{Keywords}

Heparin

Peptide nanofibers

Self-assembly

Islet transplantation

Angiogenesis

\begin{abstract}
A B S T R A C T
Pancreatic islet transplantation is a promising treatment for type 1 diabetes. However, viability and functionality of the islets after transplantation are limited due to loss of integrity and destruction of blood vessel networks. Thus, it is important to provide a proper mechanically and biologically supportive environment for enhancing both in vitro islet culture and transplantation efficiency. Here, we demonstrate that heparin mimetic peptide amphiphile (HM-PA) nanofibrous network is a promising platform for these purposes. The islets cultured with peptide nanofiber gel containing growth factors exhibited a similar glucose stimulation index as that of the freshly isolated islets even after 7 days. After transplantation of islets to STZ-induced diabetic rats, 28 day-long monitoring displayed that islets that were transplanted in HM-PA nanofiber gels maintained better blood glucose levels at normal levels compared to the only islet transplantation group. In addition, intraperitoneal glucose tolerance test revealed that animals that were transplanted with islets within peptide gels showed a similar pattern with the healthy control group. Histological assessment showed that islets transplanted within peptide nanofiber gels demonstrated better islet integrity due to increased blood vessel density. This work demonstrates that using the HM-PA nanofiber gel platform enhances the islets function and islet transplantation efficiency both in vitro and in vivo.
\end{abstract}

() 2015 Acta Materialia Inc. Published by Elsevier Ltd. All rights reserved.

\section{Introduction}

Diabetes mellitus is one of the most common diseases in the world and causes more than 200,000 deaths each year in the United States [1]. There are approximately 177 million diabetic patients worldwide and this number is expected to double by 2025 [2]. Diabetes is associated with serious complications, including cardiovascular, renal, ophthalmic, neurological, cerebrovascular, and peripheral vascular diseases [3-8].

Type 1 diabetes (T1D) is a chronic autoimmune disease and involves the destruction of or damage to the $\beta$-cells in the islets

\footnotetext{
* Corresponding authors at: Institute of Materials Science and Nanotechnology, National Nanotechnology Research Center (UNAM), Bilkent University, Ankara 06800, Turkey. Fax: +90 3122664365 (M.O. Guler and A.B. Tekinay). Pancreas Islet Cell Research Center, Ankara Diskapi Yildirim Beyazit Training and Research Hospital Etlik Polyclinic, Department of Endocrinology and Metabolism, Ankara 06800, Turkey. Fax: +90 3123170513 (T. Delibasi).

E-mail addresses: delibasi@hacettepe.edu.tr (T. Delibasi), moguler@unam. bilkent.edu.tr (M.O. Guler), atekinay@bilkent.edu.tr (A.B. Tekinay).
}

of Langerhans, resulting in insulin deficiency and hyperglycemia [9]. Since the discovery of the insulin hormone in 1921, insulin treatment has been the standard therapeutic approach to treat T1D. However, because of the fluctuation of the blood glucose levels of the patients throughout the day, insulin therapy alone was found to be insufficient for curing the disease, as acute morbidity and mortality as well as a series of chronic complications were observed after insulin treatment $[10,11]$. Although improvements in insulin delivery systems were proposed to provide strict control on blood glucose levels, there are several limitations including poor patient compliance, risk of hypoglycemia and complications caused by using devices for insulin delivery [11]. Islet transplantation has been used as a treatment for T1D to improve glycemic control in patients and rescue them from daily insulin injection [12]. This method is as effective as whole pancreas transplantation and less invasive [11]. Although it is a promising method, there are several limitations such as insufficient number of donors and decreased islet viability during and after isolation [13]. Cellular stress and disruption of islets' original integrity 
during isolation limit the success of islet transplantations $[14,15]$. Pancreatic islets tend to form clusters and in these clusters, cells, which exist in the core of the islet die due to decreased oxygen and nutrient transport. Normally, islets have extensive intra-islet vasculature to overcome these problems [16]. This vasculature is damaged during the isolation procedure, and the damaged microvasculature only regenerates after 10-14 days following the transplantation [17-20]. However, low diffusion of nutrients and oxygen leads to deterioration of cells [21] including $\beta$-cells and leads to hypoxia and death [22].

In the initial few days of transplantation using alternative transplantation sites, supportive scaffolds and minimizing the immunological responses are being investigated in order to increase the islet viability and consequently long term normoglycemia. Until now, several alternative transplantation sites such as liver through the portal venous circulation [23], spleen, kidney [24], testis [25], anterior chamber of the eye [26], and greater omentum [27] have been tested to find an effective and less invasive surgical procedure for patient safety. Due to its self-healing potential, omentum was also used for revascularization of brain [28] and heart [29], and regeneration of spinal cord [30]. It has several advantages compared to other transplantation sites which are (1) large transplantation area, (2) less direct contact with blood that prevents instant immunological response and higher blood pressure, and (3) not being a vital organ. On the other hand, it requires more islets for transplantation and enhanced blood vessel formation for transplantation efficiency [31].

During the islet isolation procedure, enzyme treatment disrupts islet-matrix interactions, which results in extracellular matrix (ECM) degradation and cell apoptosis [15,32]. Supporting the islets in in vitro conditions with matrices that contain ECM components such as collagen and fibrin increases viability of the islets [33-35] and it shows the importance of scaffolds in providing an ECMmimetic environment for islets.

In this study, peptide amphiphile (PA) nanofibers were used as a bioactive scaffold for islet transplantation. The PA molecules selfassemble into nanofibers due to intermolecular hydrogen bonding, electrostatic interaction between charged amino acids, and hydrophobic interactions [36,37]. PA nanofibers form a 3D network in aqueous environment, which resemble natural ECM and this network can be enriched with specific bioactive sequences to modulate cell-material interactions. PA nanofibers have previously been used as functional scaffolds for bone [38,39], neural [40], and cornea [41] regeneration and can also be used as drug delivery agents [42].

Here, heparin mimetic peptide amphiphile (HM-PA) nanofibers were used as a new therapeutic approach for type 1 diabetes to enhance the function of pancreatic islets and to improve the islet transplantation efficiency. The HM-PA nanofibers induce capillary-like structure formation of endothelial cells in vitro and the PA scaffold applied with vascular endothelial growth factor (VEGF) and fibroblast growth factor 2 (FGF-2), induce angiogenesis, in cornea in vivo [43]. The HM-PA provides an ECM like environment to enhance angiogenesis, which in turn enhances islet viability and functionality both in vitro and in vivo.

\section{Materials and methods}

\subsection{Materials}

9-Fluorenylmethoxycarbonyl (Fmoc) and other protected amino acids, lauric acid, [4-[ $\alpha$ - $\left(2^{\prime}, 4^{\prime}\right.$-dimethoxyphenyl $) F m o c-$ amino methyl]phenoxy] acetomidonorleucyl-MBHA resin (Rink amide MBHA resin), 2-(1H-Benzotriazol-1-yl)-1,1,3,3-tetramethyluronium hexafluorophosphate (HBTU), and diisopropylethylamine (DIEA) were purchased from Merck. ABCR Collagenase V and Streptozotocin (STZ) were purchased from Sigma-Aldrich. RPMI 1640, Hanks Balanced Salt Solution (HBSS), Fetal Bovine Serum (FBS), penicillin/streptomycin/amphotericin B and L-glutamine were purchased from Lonza. Biocoll 1100 and Biocoll 1077 were purchased Biochrom. Rat-Mouse Insulin Assay and cell inserts were purchased from Milipore. VEGF was purchased from R\&D and human FGF-2 from Sigma-Aldrich. All chemicals were used as provided.

\subsection{Synthesis and purification of peptide amphiphile molecules}

Peptide molecules were synthesized by solid-phase Fmoc peptide synthesis method. HM-PA (Lauryl-VVAGEGD(K-pbs)S-Am) and K-PA (Lauryl-VVAGK-Am) were constructed on Rink Amide MBHA resin via the solid phase peptide synthesis method. Coupling was performed with 1 equivalent of MBHA resin, 2 equivalent of Fmoc protected group amino acid, 1.95 equivalent of HBTU and 3 equivalent of $\mathrm{N}, \mathrm{N}$-diisopropylethylamine (DIEA) for $2 \mathrm{~h}$. Fmoc removal was performed with $20 \%$ piperidine/dimethylformamide solution (DMF) for $20 \mathrm{~min}$. 10\% acetic anhydride/DMF was used as blocking agent for the remaining free amine groups after coupling. The resin was washed three times with DMF, dichloromethane (DCM) and DMF, respectively. In order to synthesize HM-PA, sulfobenzoic acid was added to the side chain of lysine. Before this process, 4-methyltrityl (MTT) group, which provides side chain protection for lysine, was removed by a trifluoroacetic acid (TFA)/triisopropylsilane (TIS)/ $\mathrm{H}_{2} \mathrm{O} / \mathrm{DCM}$ mixture (5:2.5:2.5:90 ratio) for $5 \mathrm{~min}$. Then, peptide cleavage was performed with 95:2.5:2.5 TFA:TIS: $\mathrm{H}_{2} \mathrm{O}$ for $2 \mathrm{~h}$ at room temperature. After cleavage reaction, PA molecules were collected in a clean round bottomed flask and DCM wash was performed several times. Excess TFA was removed by a rotary-evaporator. After evaporation, ice-cold diethyl ether was added into the PA solution and the resulting white precipitate was dried under vacuum. PAs were characterized by liquid chromatography and mass spectrometry (LC-MS). Mass spectrum was obtained with Agilent 1200 LC-MS equipped with Agilent 6530 Q-TOF with an ESI source and Zorbax Extend-C18 $2.1 \times 50 \mathrm{~mm}$ column for basic conditions and Zorbax SB-C8 $4.6 \mathrm{~mm} \times 100 \mathrm{~mm}$ column for acidic conditions. A gradient of water $\left(0.1 \%\right.$ formic acid or $\left.0.1 \% \mathrm{NH}_{4} \mathrm{OH}\right)$ and acetonitrile $\left(0.1 \%\right.$ formic acid or $\left.0.1 \% \mathrm{NH}_{4} \mathrm{OH}\right)$ was used. Purification of PAs was performed by using a reverse phase preparative highperformance liquid chromatography (HPLC) (Agilent 1200 series) system by using Zorbax Extend-C18 $21.2 \times 150 \mathrm{~mm}$ column.

\subsection{Physical, mechanical and chemical characterization of self- assembled nanofiber network}

\subsubsection{Transmission electron microscopy (TEM)}

The morphology of self assembled PA nanostructure was characterized by transmission electron microscopy (TEM). $10 \mu \mathrm{L}$ of the PA solution was deposited on a Lacey carbon-coated 300-mesh copper grid and incubated for $3 \mathrm{~min}$. Excess solution was removed by tissue paper and the sample was negatively stained with $2 \mathrm{wt} \%$ uranyl acetate and dried at room temperature. Images were visualized by a FEI Tecnai G2 F30 transmission electron microscope.

\subsubsection{Atomic force microscopy (AFM)}

PA solutions that were dissolved in water were prepared by mixing 0.05 wt\% HM-PA with K-PA at 1:1 volume ratio on a silicon wafer. After the sample was dried at room temperature for $30 \mathrm{~min}$, AFM images were taken via MFP-30 Asylum Research in tapping mode using the appropriate cantilever. All images were taken with $1.0-1.5 \mathrm{~Hz}$ scan rate and $1024 \times 512$ resolution. Tips with resonance frequency of $246 \mathrm{kHz}$ were used. 


\subsubsection{Scanning electron microscopy (SEM)}

The three dimensional nanofibrous network of PA molecules was investigated using scanning electron microscopy (SEM). 1\% $w / v$ PA solutions were mixed with the volume ratio of $1: 1$ to achieve gel formation. Gels were incubated for 15 min for maturation and dehydrated gradually with increasing concentrations of ethanol for 2 min each. Samples were dried in a critical point dryer (Tousimis, Autosamdri-815B, Series C critical point dryer) and coated with $8 \mathrm{~nm}$ of Au/Pd. SEM imaging of the nanofiber networks was taken with an FEI Quanta 200 FEG scanning electron microscope under high vacuum.

\subsubsection{Circular dichroism (CD)}

Secondary structure of PA molecules was investigated by $C D$ analysis using JASCO J815 CD spectrapolarimetry. PA solutions were dissolved in deionized water at a concentration of $0.01 \%$ $\mathrm{w} / \mathrm{v}$ and $\mathrm{pH}$ was adjusted to 7.4. The CD spectra of HM-PA, K-PA and HM-PA/K-PA (1:1 volume ratio) were obtained from scanning at $190 \mathrm{~nm}$ to $300 \mathrm{~nm}$ using a digital integration time of $1 \mathrm{~s}$, a band width of $1 \mathrm{~nm}$ and with standard sensitivity.

\subsection{Animals}

In vivo experiments were carried out with 3 month old Wistar male rats for both syngeneic islet donors and islet recipients. Rats were maintained on ad libitum access to water and nutrition in a 12-12 h light-dark cycle except the day before transplantation. All procedures regarding animals were approved by Institutional Animal Care and Use Committee of Diskapi Yildirim Beyazit Training and Research Hospital.

\subsection{Islet isolation and culture}

Cell culture studies were carried out with isolated syngeneic primary pancreatic islets. The pancreas islet isolation was done according to methods modified from other studies [44-46]. Briefly, rats were anesthetized by an intraperitoneal injection of ketamycin $(80 \mathrm{mg} / \mathrm{kg})$ and xylazine $(20 \mathrm{mg} / \mathrm{kg})$. Then midline laparotomy was performed, and the common bile duct was cannulated. The $1 \mathrm{mg} / \mathrm{mL}$ concentration of collagenase Type $\mathrm{V}$ enzyme solution was prepared in cold Hanks' Balanced Salt Solution. Following the injection of $7 \mathrm{~mL}$ of cold collagenase (Type V, $1 \mathrm{mg} / \mathrm{mL}$ ) into the duct with a $22 \mathrm{G}$ cannula, the distended pancreas was removed and subjected to stationary digestion for 18 min at $37^{\circ} \mathrm{C}$. At the end of the incubation time, cold HBSS supplemented with $10 \%$ FBS, $1 \%$ L-glutamine and $1 \%$ PenicillinStreptomycin-Amphotericin B was added for inhibition of enzyme activity and washing. After the digested pancreas was centrifuged for $3 \mathrm{~min}$ at $300 \mathrm{~g}$ with slow brake, the supernatant was removed gently. The pellet suspension was filtered by a steel sieve of $450 \mu \mathrm{m}$ to remove islets from undigested tissue. Subsequently, the islets were purified by using Biocoll $1100(1100 \mathrm{~g} / \mathrm{mL})$, Biocoll $1077(1077 \mathrm{~g} / \mathrm{mL})$ and RPMI 1640 to create a discontinuous gradient and were centrifuged for $20 \mathrm{~min}$ at $1100 \mathrm{~g}$ with slow brake. After purification, the islets were washed with RPMI 1640 supplemented with $10 \%$ FBS, $1 \%$ L-Glutamine and $1 \%$ PenicillinStreptomycin-Amphotericin B. Islets were counted and picked up under an optical microscope via the handpick method. Islet cells were cultured with $10 \%$ FBS $1 \%$ penicillin/streptomycin/ amphotericin B and 1\% L-glutamine supplemented RPMI 1640 at $37^{\circ} \mathrm{C}$ under the humidified atmosphere containing $5 \% \mathrm{CO}_{2}$ incubator.

\subsubsection{Pancreatic islet viability}

Viability was assessed by normalizing to DNA content using Alamar Blue Assay (Invitrogen) and FluoReporter Blue
Fluorometric dsDNA Quantitation Kit (Invitrogen) by using 50 islets sized between 100-200 $\mu \mathrm{m}$. After incubating islets for $24 \mathrm{~h}$, six experimental conditions were constituted: (1) media only as a control group; (2) media with HM-PA and K-PA; (3) media with HM-PA; (4) media with VEGF and FGF-2; (5) media with HM-PA, VEGF and FGF2; (6) media with HM-PA, K-PA, VEGF and FGF2. RPMI 1640 with $1 \%$ L-glutamine and $1 \%$ penicillin/streptomycin/ amphotericin B was used as culture media. PA solutions were added to the media at the final concentration of $0.1 \% \mathrm{w} / \mathrm{v}$ HM-PA and $0.1 \% \mathrm{w} / \mathrm{v}$ K-PA (1:1 volume ratio) and the growth factor amounts were determined as $100 \mathrm{ng}$. The experiment was performed at days 1, 3 and $7(n=4)$. Before starting the Alamar Blue Assay, islets were collected and transferred into tissue culture inserts $(8 \mu \mathrm{m}$ pore size, Millicell). Alamar Blue stock solution was diluted to $1: 10$ with the culture medium and incubated with islets at $37^{\circ} \mathrm{C}$ with $5 \% \mathrm{CO}_{2}$ for $4 \mathrm{~h}$. At the end of the $4 \mathrm{~h}$, absorbance was monitored at $570 \mathrm{~nm}$. The inserts with islets were kept at $-80^{\circ} \mathrm{C}$ for DNA quantification. In order to quantify DNA amounts, islet samples were thawed at room temperature and $200 \mu \mathrm{L}$ of $\mathrm{ddH}_{2} \mathrm{O}$ was added into each well. Plates were incubated in a humidified incubator $\left(37^{\circ} \mathrm{C}, 5 \% \mathrm{CO}_{2}\right)$ for $1 \mathrm{~h}$, and then frozen at $-80^{\circ} \mathrm{C}$ for $2 \mathrm{~h}$ to disrupt the cell membrane. Afterward, cells were thawed at room temperature again and Hoechst 33258 dye in TNE (10 mM Tris, $2 \mathrm{M} \mathrm{NaCl}, 1 \mathrm{mM}$ EDTA, pH 7.4, containing $2 \mathrm{mM}$ sodium azide) was added into wells with the volume of $200 \mu \mathrm{L} /$ well. $200 \mu \mathrm{L}$ from this solution was transferred to a 96 well plate and fluorescence was read at $360 \mathrm{~nm}$ and $460 \mathrm{~nm}$ by a microplate reader. The ratio of viability and DNA was calculated by dividing the Alamar Blue Assay results by DNA Assay results.

\subsubsection{Glucose stimulated insulin release}

Islets were handpicked to have a size distribution of $150-200 \mu \mathrm{m}$ in diameter, and cultured (10 islets each well) on tissue culture inserts $(8 \mu \mathrm{m}$ pore size) (Millipore, Billerica, MA) for $24 \mathrm{~h}$ before they were processed for evaluation of glucose stimulated insulin release. Islets were washed with RPMI 1640 medium containing $3.3 \mathrm{mM}$ glucose for $30 \mathrm{~min}$. Following the wash, islets were sequentially incubated in $3.3 \mathrm{mM}$ glucose and $16.7 \mathrm{mM}$ glucose containing media at $37^{\circ} \mathrm{C}, 5 \% \mathrm{CO}_{2}$ for $1 \mathrm{~h}$. Before medium changes, media were collected and stored at $-20^{\circ} \mathrm{C}$. Experiments were carried out on days 1,3 and 7. Glucose stimulation assay was performed via Rat/Mouse Insulin 96 Well Plate Assay, ELISA Kit, Millipore as instructed by the manufacturer. Insulin release was quantified as a ratio of high glucose to low glucose state and presented as the stimulation index.

\subsection{Transplantation}

10 days before transplantation, $220 \mathrm{mg} / \mathrm{kg} \mathrm{STZ}$ which was present in the citrate buffer $(0.1 \mathrm{M}, \mathrm{pH} 4.5)$ was injected into rats intraperitoneally to induce diabetes. Blood glucose levels of the rats were measured using an On Call Advanced Blood Glucose Monitoring System (Acon Laboratories Inc., CA USA). Blood glucose levels of rats were measured at days 5 and 3 before transplantation, and only animals with blood glucose levels of $>300 \mathrm{mg} / \mathrm{dL}$ at both days were used for transplantation experiments. 2000 islets were transplanted into the omentum of each rat. Isolated islets with a minimal volume of medium were mixed with HM-PA and then, gelation was triggered with the addition of K-PA. The final concentrations of PA solutions in scaffold were $1 \%$ $\mathrm{w} / \mathrm{v}$ HM-PA and $1 \% \mathrm{w} / \mathrm{v}$ K-PA at $1: 1$ volume ratio.

An intraperitoneal injection of ketamycin $(80 \mathrm{mg} / \mathrm{kg})$ and xylazine $(10 \mathrm{mg} / \mathrm{kg})$ was used as anesthetic agents. The abdominal region of rats was shaved and sterilized with antiseptic solution (BATTICON solution, Adeka, Turkey). A greater omentum was reached by a lower abdominal incision and it was spread onto a 
wet sterile gauze pad. Islets with PA gel were placed onto the omentum, and the omentum was sewed with 3.0 PGLA (90\% glycolide and $10 \%$ L-lactide) surgical sutures as a pouch model. After the procedure, animals were administered $1000 \mathrm{mg} / \mathrm{kg}$ cefazolin (Mustafa Nevzat, Turkey) subcutaneously. Recipient rats were classified as (i) control (untreated), $(n=7)$, (ii) sham $(n=7)$, (iii) PA ( $n=7)$, (iv) islet ( $n=7)$, (v) PA + islet groups $(n=7)$.

PA gels without islets were transplanted to serve as negative control (PA group). A sham group, comprising animals that have undergone surgery but did not receive PA or islet transplantation, was also included in the study. Animal omentum was sewed as a pouch model. Healthy rats showing normal blood glucose levels were used as a positive control. Animals in the islet group were transplanted with only islets but no PA gel. Rats were allowed to eat and drink freely after the operation and routine controls were done throughout the study for infection.

\subsection{Scaffold function assessment}

After transplantation, non-fasting blood glucose levels and weight of the animals were measured three times a week for 28 days. The graft was considered to be functional only if the blood glucose levels of the recipients were less than $300 \mathrm{mg} / \mathrm{dL}$. Intraperitoneal glucose tolerance test (IPGTT) was performed at 28 days after transplantation to measure the effect of glucose challenges. After fasting overnight, rats were injected with glucose solution $(2 \mathrm{~g} / \mathrm{kg})$ intraperitoneally after intraperitoneal injection of anesthetic agents; ketamycin $(80 \mathrm{mg} / \mathrm{kg})$ and xylazine $(10 \mathrm{mg} /$ $\mathrm{kg}$ ). Blood glucose levels were measured from the tail vein at the baseline (before injection), 5, 10, 15, 30, 60, 90 and 120 min after injection.

\subsection{Histological analysis}

At the end of 28 days, rats were anesthetized and transcardially perfused with saline and formalin, respectively. Omentum and pancreas tissues were collected and fixed in formalin for approximately $18 \mathrm{~h}$ before being embedded into paraffin. Tissues were sectioned with a Leica microtome at $5 \mu \mathrm{m}$ thickness. Sections were deparaffinized in xylene and rehydrated in serial ethanol series for hematoxylin \& eosin (H\&E) staining and Masson's trichrome staining according to the standard protocol. For immunohistochemistry experiments, sections were stained with anti-insulin (1:500; Sigma I2018, clone K36AC10), anti-macrophages/monocytes (1:300; Millipore, MAB1435, clone ED-1) and anti-von Willebrand Factor (1:200; Abcam, ab6994) antibodies. After primary antibody staining, horseradish peroxidase conjugated goat anti-mouse secondary antibody (1:500; Millipore) was used followed by 3,3'-diaminobenzidine (DAB) staining. All samples were mounted onto glass slides using xylene based mounting medium. Digital images were acquired via Zeiss Axio Scope A1. For vascular density quantification, each paraffin-embedded omentum tissue was serially sectioned and 5 matching slides were selected from each tissue for quantification with approximately $100 \mu \mathrm{m}$ intervals. Images were acquired by using a $20 \times$ objective.

\subsection{Statistical analysis}

Statistical analyses were performed using two-way ANOVA or one-way ANOVA with Bonferonni multiple comparison test. The level of significance was set at $p<0.05\left({ }^{*} p<0.05 ;{ }^{* *} p<0.01\right.$; $\left.{ }^{* * *} p<0.001\right)$. Error bars indicate standard error of mean.

\section{Results}

\subsection{Heparin mimetic PA molecules self-assemble into nanofibers}

The HM-PA was functionalized with bioactive chemical groups to mimic heparin structure and function (Fig. 1Ai) [43]. Non-bioactive positively charged K-PA was synthesized in order to induce nanofiber formation through charge neutralization after mixing with HM-PA (Fig. 1Aii). All peptide molecules were characterized by liquid chromatography-mass spectrometry (LC-MS) and purified by preparative HPLC (Figs. S1 and S2). $\beta$-Sheet-driven nanofiber elongation was provided via the VVAG motif and analyzed by circular dichroism (CD) spectroscopy. CD results showed that $\beta$ sheet structure dominates the HM-PA/K-PA mixture with a negative band at $218 \mathrm{~nm}$ and a positive band at $195 \mathrm{~nm}$ (Fig. 1B). SEM image demonstrated the formation of a porous nanofiber network when HM-PA and K-PA were mixed (Fig. 1C). AFM and TEM images of PA molecules revealed that nanofibers were uniform in width and were c. 20-30 $\mathrm{nm}$ in diameter (Fig. 1D and E).

\subsection{HM-PA improves function of islets in vitro}

A viability analysis was performed to investigate the effect of HM-PA on pancreatic islets. Viability of cultured islets sized between 100 and $200 \mu \mathrm{m}$ in diameter was determined over a 7day period using Alamar Blue assay. In our previous study, HMPA was shown to have a high binding affinity to VEGF, and FGF-2 [47]. Since FBS contains high amounts of growth factors [48], evaluation of islet viability and function was performed in serum-free conditions. One hundred ng of FGF-2 and VEGF were added to the culture media where indicated, in order to assess the effect of growth factor supplementation. During 7 days of culture, although islets tended to cluster in other groups, islets cultured with HMPA/K-PA nanofibers did not form clusters (Fig. 2). Viability measurements indicated that HM-PA/K-PA combinations with and without growth factors showed higher viability at day 1 and day 3 (Fig. 2B). However, day 7 results were similar between all experimental groups.

It is known that increased cellular viability or activity does not indicate enhanced functionality because of the tendency of islets to lose their insulin release capabilities [49]. Thus, insulin release capacities of cultured islets in response to low versus high glucose concentrations were measured with an ultrasensitive rat insulin ELISA (Fig. 3). After 1 day of culture, HM-PA and the combination of HM-PA and growth factors had $5.7 \quad(p<0.001)$ and 4.9 $(p<0.01)$ times greater glucose stimulation indices (GSI), respectively, compared to the freshly isolated islets (Fig. 3A). At day 3, though all experimental groups displayed a decreased value of GSI compared to day 1, islets cultured with HM-PA/K-PA and GFs had the highest GSI (not statistically significant) (Fig. 3B). However, after 7 days, islets cultured with HM-PA/K-PA and GFs showed a GSI of 0.98 which was similar to freshly isolated islets (1.25) (Fig. 3C).

\subsection{Transplantation within bioactive PA scaffold improves glucose responsiveness of the transplanted islets}

Islets with or without PA gel were transplanted into the omentum of STZ-induced diabetic rats under general anesthesia. For transplantation, the omentum was reached through the abdominal cavity with a small incision. Islets with or without the PA gel scaffold were placed onto it, and finally they were sewed together as a pouch (Fig. 4A-D). No complications were observed during and after the surgery. Blood glucose levels of recipient rats $(n=7)$ are 
A)

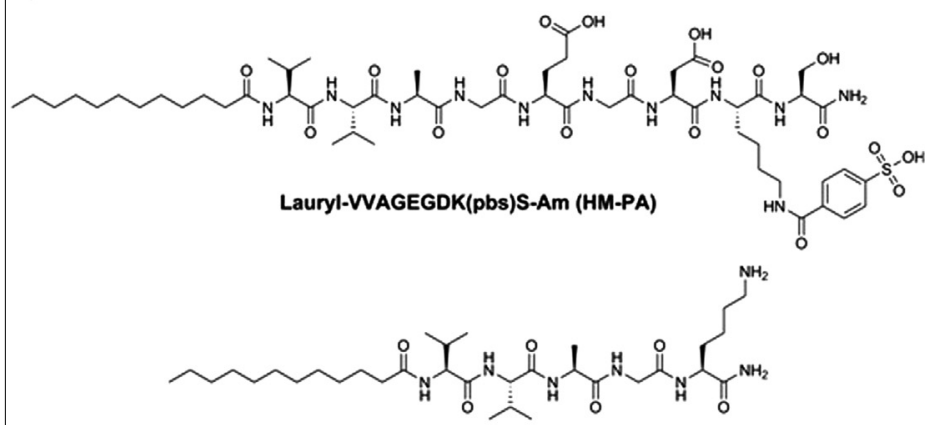

B)

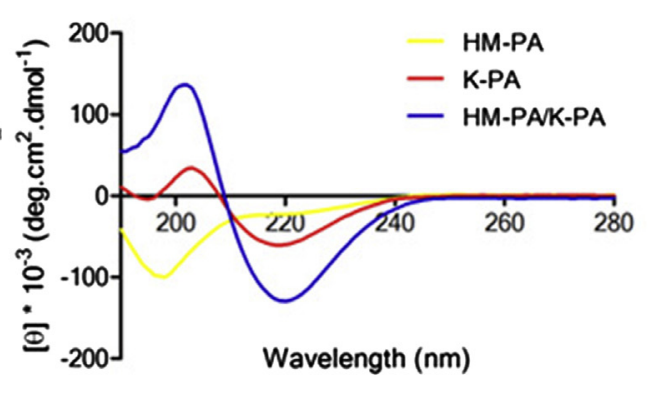

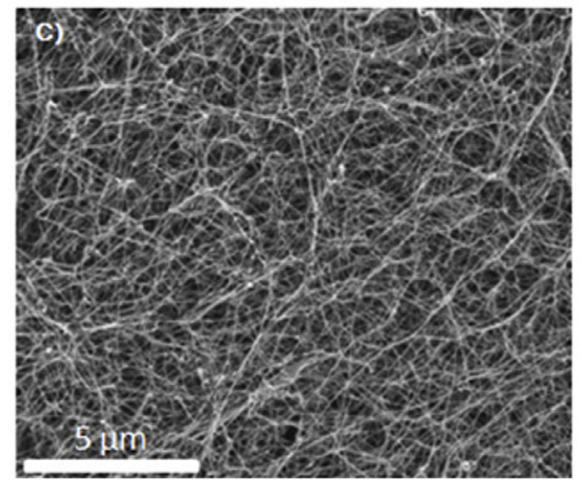
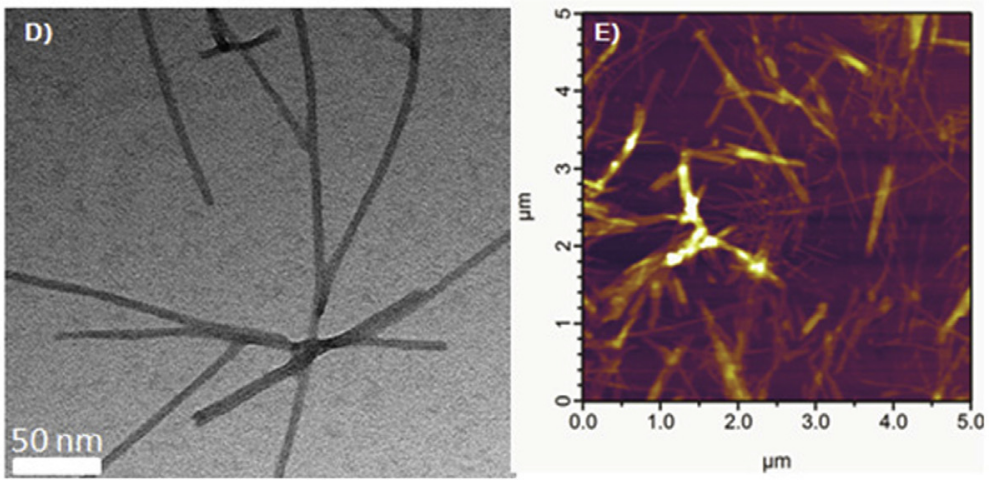

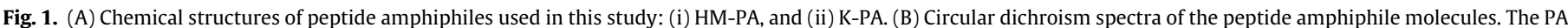

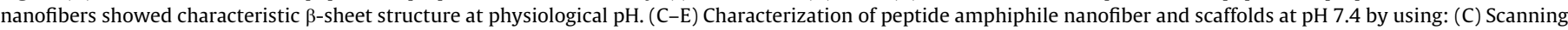
electron microscopy, (D) transmission electron microscopy, and (E) atomic force microscopy. Scale bars are $5 \mu \mathrm{m}$ (C) and $50 \mathrm{~nm}$ (D).

(A)

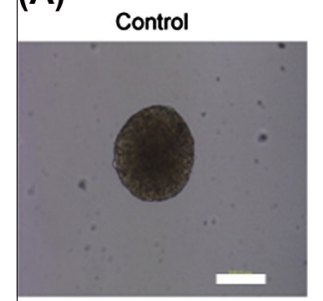

(B)

Day 1

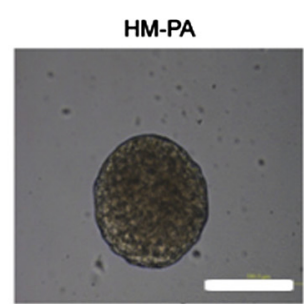

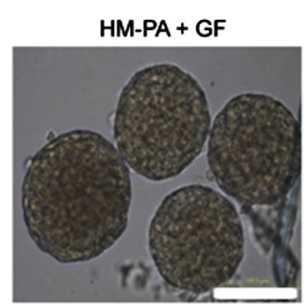

Day 3

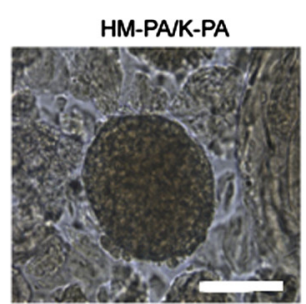

Day 7
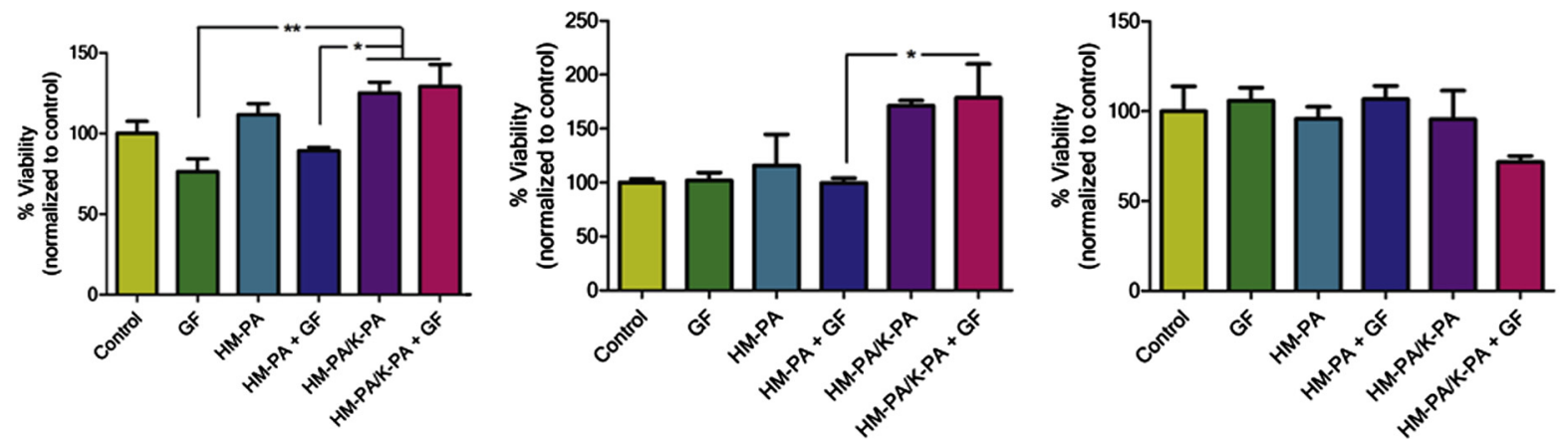

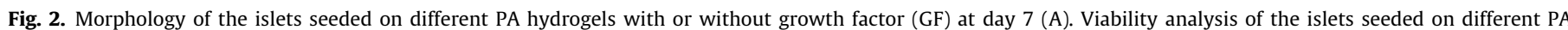
hydrogels with or without growth factor (GF) by using the Alamar blue assay at day 1, day 3 and day 7 (B). Scale bars are $100 \mu \mathrm{m}$. [GF = VEGF + FGF-2].

shown in Fig. 5A. When islets were transplanted with the PA scaffold, 2 out of 7 recipients maintained normal glucose levels and 4 out of 7 had blood glucose levels less than $270 \mathrm{mg} / \mathrm{dL}$ over the course of 28 days. "Only islets" group showed higher blood glucose levels than "islets with PA scaffold" group. Weight of the animals in all experimental groups did not show a significant change during 28 days (Fig. S3).

To investigate the glucose responsiveness of animals transplanted with islets and the PA scaffold, we performed the intraperitoneal glucose tolerance test (Fig. 5B). The blood glucose level was 


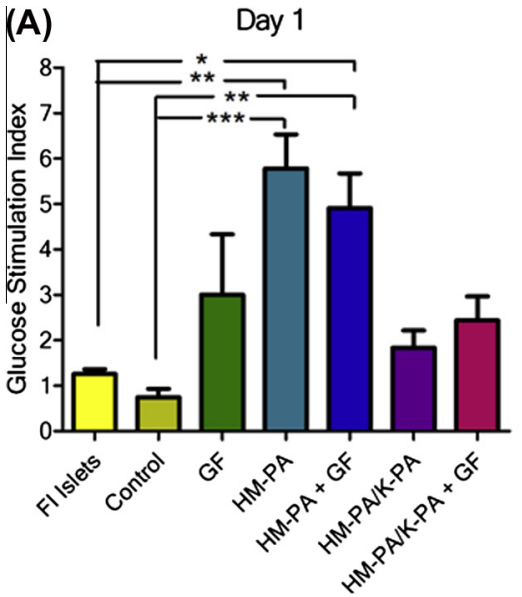

(B)

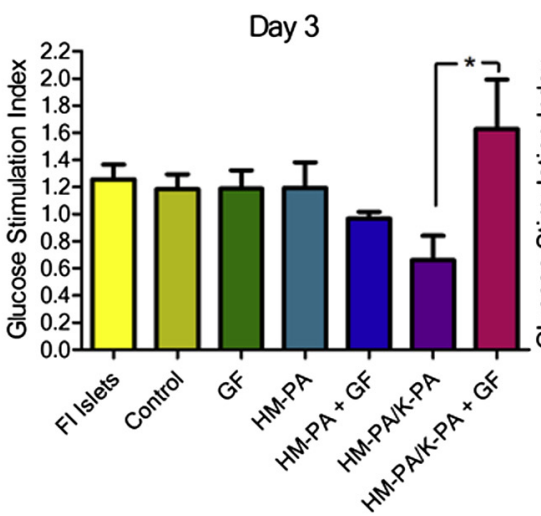

(C)

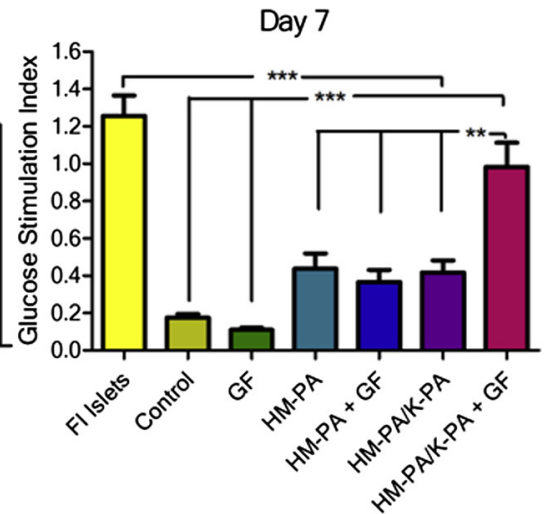

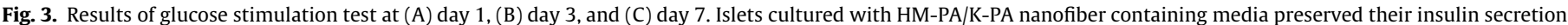
capability for 7 days better compared to other groups.
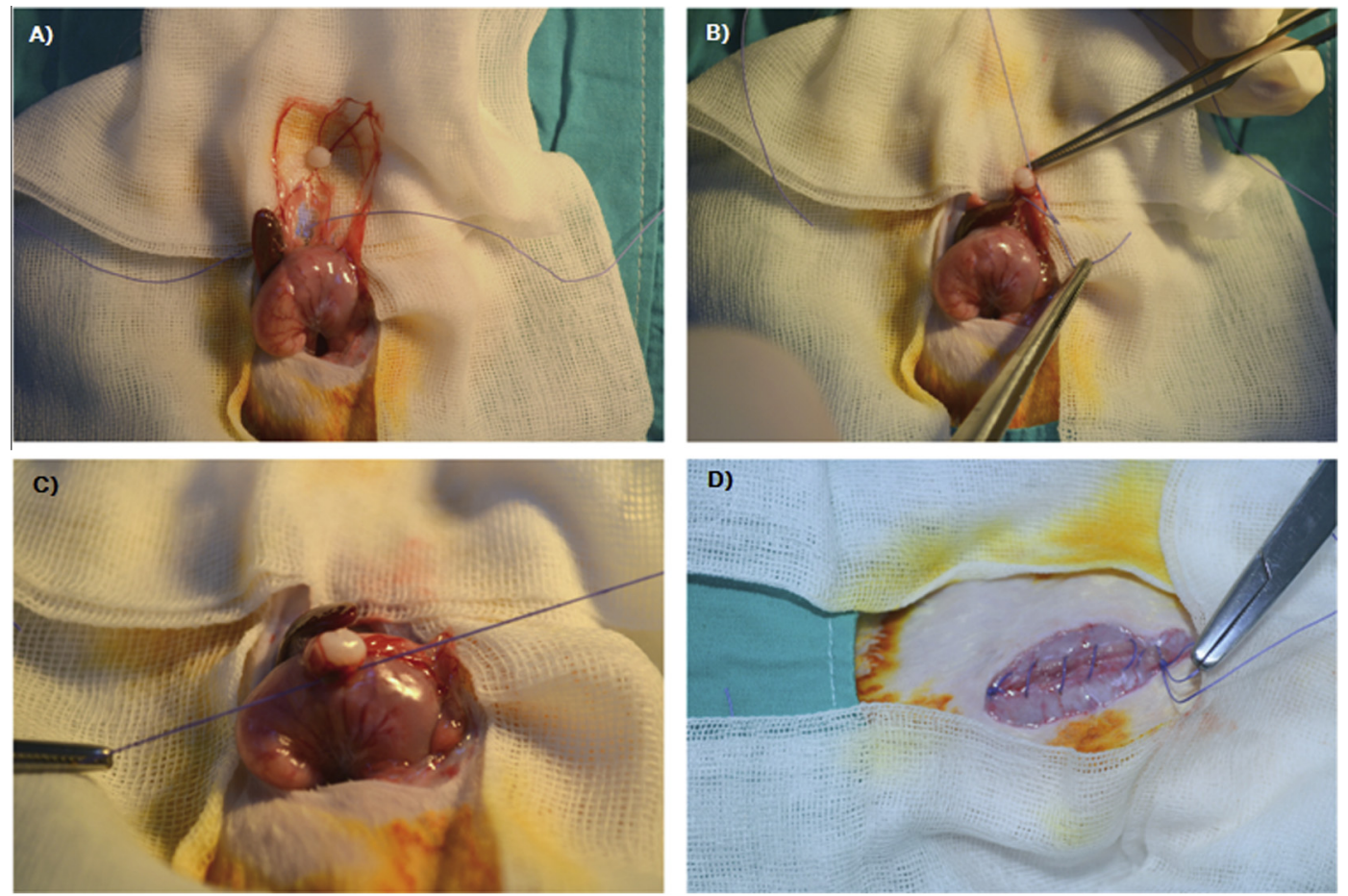

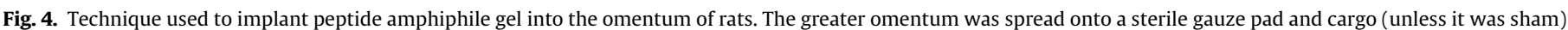

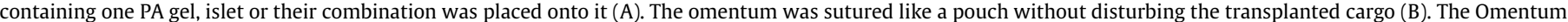
and stomach were placed back into the abdomen (C) and the abdomen was sutured (D).

still increased at 90 min after glucose administration, followed by a decrease after that point for both "control" and "islets transplanted with PA scaffold" groups. However, the other experimental groups did not show this blood glucose level pattern.

Although blood glucose levels typically start decreasing within 30 min in IPGT tests, no such trend was observed in our experimental groups, except for a very slight decrease in the control group. This was probably caused by the administration of general anesthetics ketamycin and xylazine, which are known to interfere with IPGTT results [50].

\subsection{PA scaffold supports islet integrity and enhance vascular density of the transplantation site}

In order to monitor morphology of the transplanted islets on day 28 post-transplantation, hematoxylin and eosin and Masson's trichrome stainings were carried out on omentum sections. Hematoxylin and eosin staining revealed that "peptide gel only" transplanted group showed regular omentum morphology and some peptide gel was still observable in the omentum (Fig. 6A and B) although most of the gel was degraded by day 28 . The transplanted islets were observed to be in the group where islets were transplanted with the PA gel, compared to the only islet group which was more intact and had normal morphology (Fig. 6C and D). This result shows that the PA gel helps islets to maintain their integrity for up to 28 days. Immunohistochemical staining showed that viable islets at the transplantation site were positive for insulin, indicating that they were still functioning on day 28 post-transplantation, and islets transplanted with the PA gel were more intact (Fig. 6F-H). Masson's trichrome staining suggests that collagen is present in the islets belonging to "only PA", "only islet" and "islets in PA 
(A)

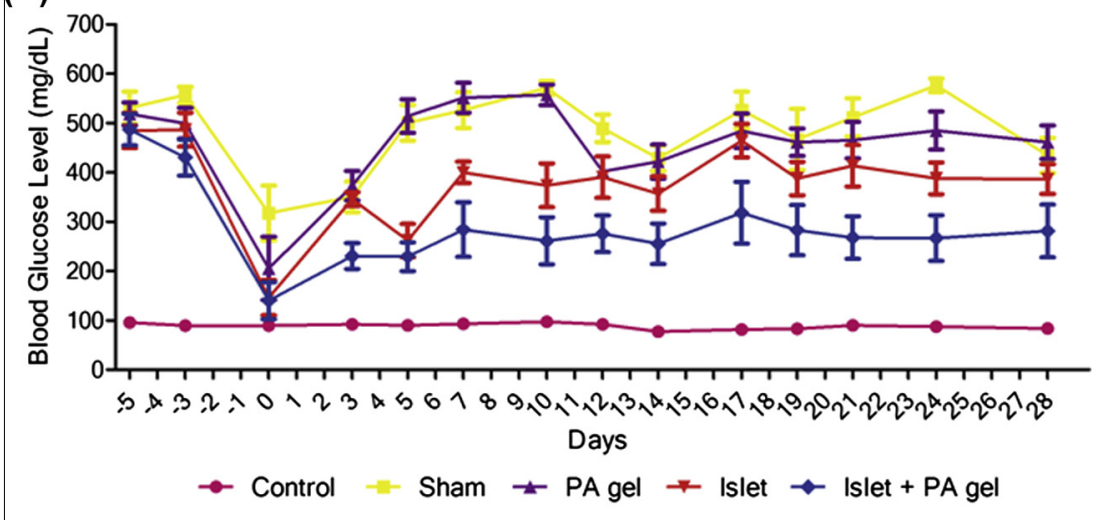

(B) IPGTT

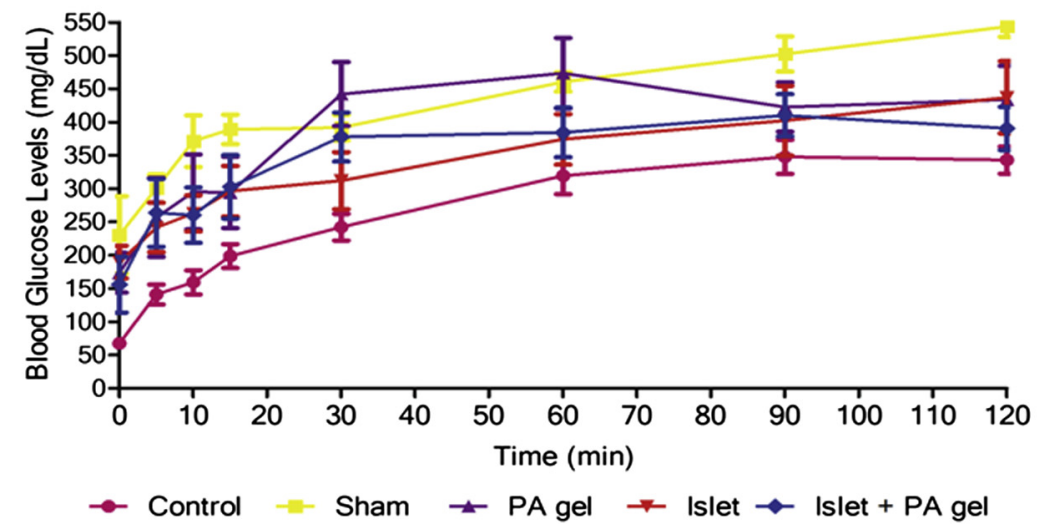

Fig. 5. (A) Blood glucose levels throughout 28 days (day 0; transplantation day) (B) intraperitoneal glucose tolerance test (IPGTT) at the end of 28 days.
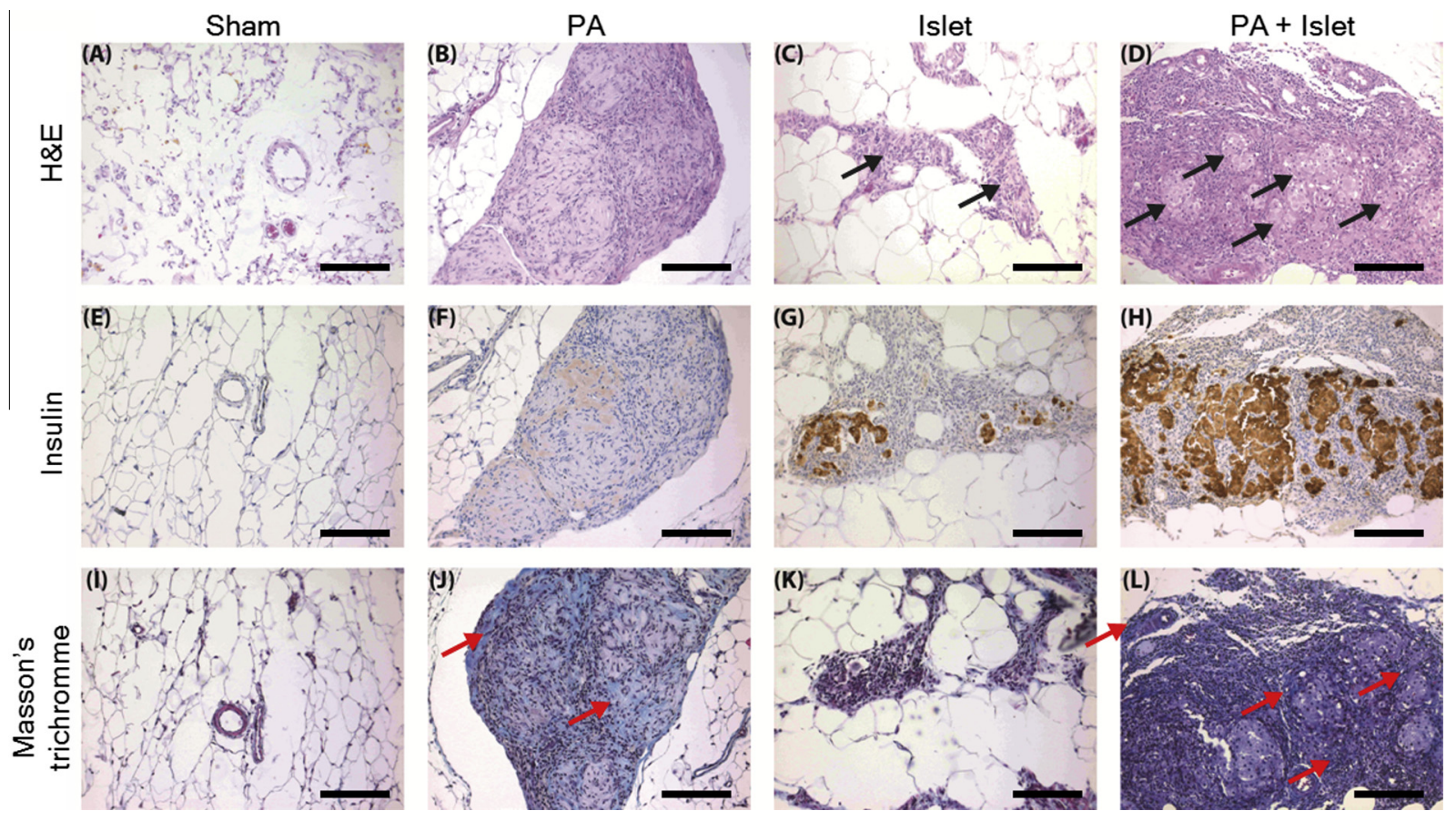

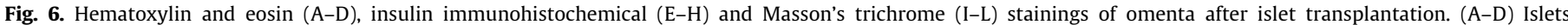

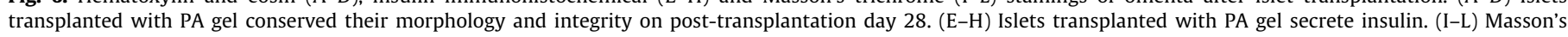

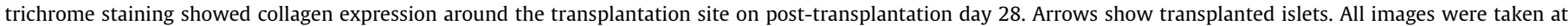
$200 \times$ magnification. Scale bars are $100 \mu \mathrm{m}$. 
gel" groups, indicating fibroblast action around the transplantation site (Fig. 6J-L).

Immunological response was visualized with macrophage staining (Fig. S4). Macrophage presence was observed to be more extensive around the islets in the "only islet" group compared to the "islets in PA gel group" (Fig. S4).

In order to observe blood vessels in omenta, anti-von Willebrand Factor staining was performed, as a vascular endothelial cell marker (Fig. 7). Newly formed blood vessels within the PA gel and islets were observed in "PA only", "islet only" and "islets in PA gel" groups (Fig. 7B-D). We also assessed the number of intraomental vascularization with 10 images per section and in a total of 5 sections from the omentum of each animal (Fig. 7E). This assessment revealed "only PA" and "islets in PA gel" groups had a significantly more intraomental vessel number than those of other groups. Additionally, there was a significant difference between the sham group and groups containing PA $(p<0.001)$, which demonstrate that PA itself promotes vascularization. The absence of statistical difference between "sham" and "only islet" groups and the presence of a statistical significant difference between "only islet" and "islet with PA groups" $(p<0.05)$ proved the fact that increased vascularization was provided by HM-PA.

\section{Discussion}

Islet transplantation is currently the most promising therapeutic method for diabetes treatment. Angiogenesis is crucial for viability and functionality of islets after transplantation. In this study, we utilized a bioactive peptide nanofiber system for enhancing viability and functionality of islets in vitro and in vivo. These nanofibers are formed through the self-assembly of short peptide amphiphile molecules (HM-PA) that were designed to mimic heparin, since heparin is important in angiogenesis and growth factor binding. HM-PA was previously shown to enhance angiogenesis in vitro and in vivo through its interactions with heparin-binding proangiogenic growth factors and their receptors [51]. In this work, we used a positively charged peptide amphiphile, K-PA, which is designed to induce nanofiber formation when mixed with negatively charged HM-PA via electrostatic interactions and hydrophobic collapse at physiological pH [52]. Secondary structure characterization proved that $\beta$-sheets drive the nanofiber formation (Fig. 1) [53].

Pancreatic islets are normally surrounded by ECM elements that provide mechanical support and cellular signaling in the normal pancreas. Because it affects the metabolic activity, it is important
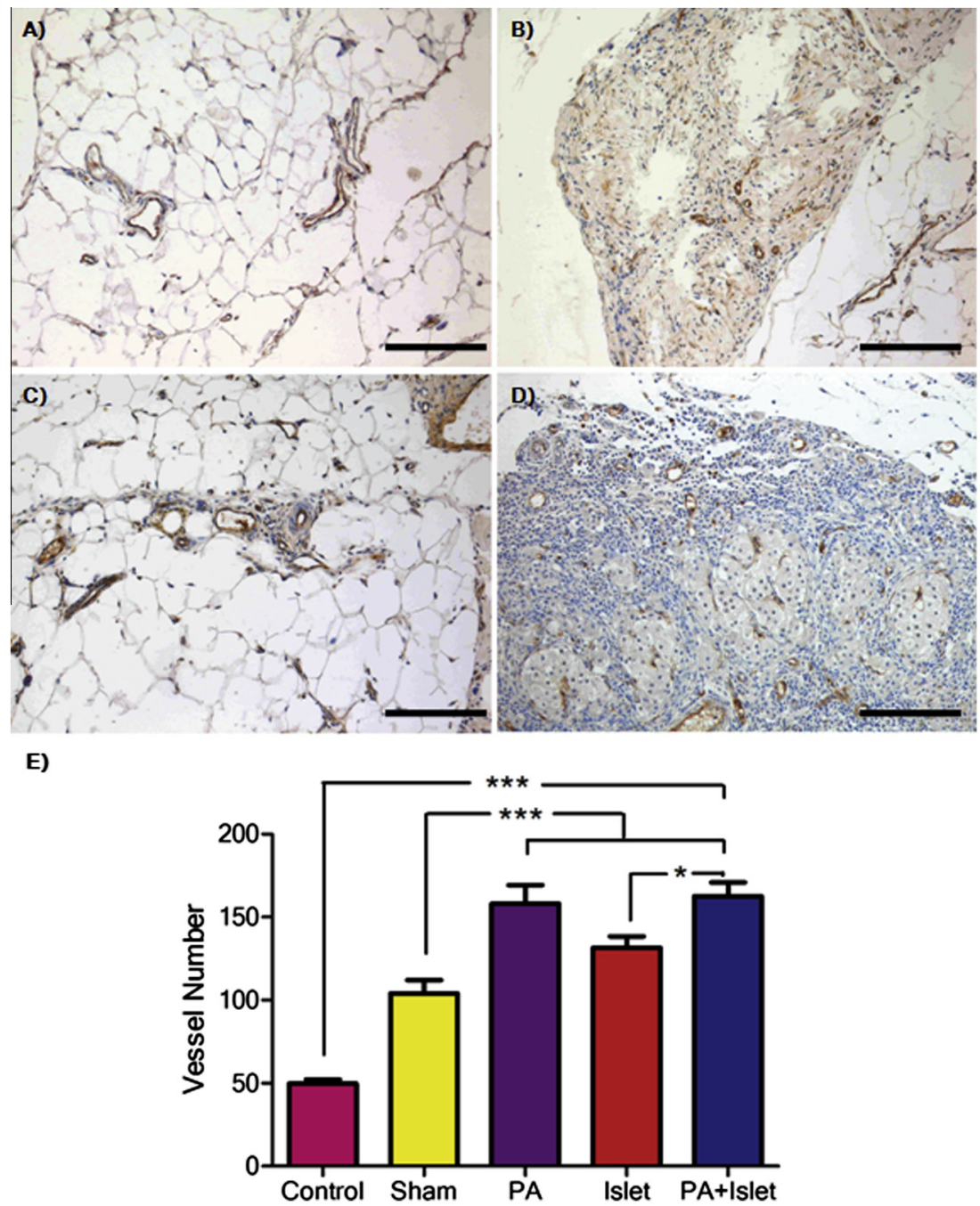

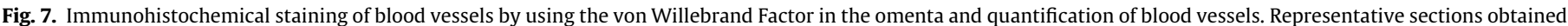

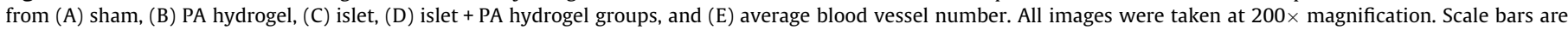
$100 \mu \mathrm{m}$. 
to preserve the morphology and integrity of the islets in in vitro conditions prior to the transplantation process [54]. Moreover, vascular network integrity and cell-matrix interactions are diminished during isolation, resulting in a decrease in metabolic function [55]. Thus, scaffolds and materials that can enhance islet viability and function prior to and during the transplantation process will be extremely valuable for the success of diabetes therapy. While designing materials to mimic the natural ECM, it is important not only to provide cells with the necessary mechanical support, but also to have enough porosity for diffusivity of required components in the microenvironment. The natural nanofibers comprising the ECM network are formed by glycosaminoglycans and other fibrous and non-fibrous biomolecules [56]. In this study, we utilized glycosaminoglycan mimetic peptide nanofiber scaffolds to provide the required support and retain islet shape without causing any toxic effect (Fig. 2). In this way, cultured islets maintained their glucose-responsive insulin secretion capability to an extent comparable to freshly isolated islets. We observed increased viability of cultured islets at days 1 and 3 when kept in the HM-PA/K-PA combinations. The similarity between all experimental groups at day 7 could have been caused by culturing in serum-free media, since all in vitro experiments were performed in serum-free conditions to eliminate external effects of serum, which contains several growth factors, proteins and transcription factors (Fig. 3) [48,57]. However, although the islets showed similar viability profiles between groups at day 7 , the islets cultured in HM-PA/K-PA nanofiber containing media showed a significant enhancement of functionality compared to other groups, assessed by glucose stimulation assay. The surprising similarity between the responses of islets cultured in HM-PA/K-PA nanofiber containing media for 7 days and freshly isolated islets shows the effectiveness of this nanofiber system for in vitro preservation of pancreatic islets. Previously, it was shown that bioactive scaffolds such as collagen, fibrin or fibronectin increase the insulin secretion of islets $[35,34]$. In addition, when growth factor cocktails are added into the system, islets can maintain their spherical morphology and give the highest insulin secretion [33]. It is also known that islet damage correlates with diminishing of insulin. Bennet et al. showed that when islets were cultured with heparin, the islet damage was reduced [58]. The success of our day 7 results may arise because our system has both heparin mimetic bioactive peptide scaffolds and growth factors. Encouraged by these in vitro findings, our heparin mimetic gel system was analyzed for their effectiveness as a scaffold system for islet transplantation in vivo.

The omental pouch model (Fig. 4) was used for transplantation [59] since transplantation of islets to the omental site both protects them from high blood pressure and provides large transplantation volume [31]. After transplantation, islets transplanted within HMPA decreased blood glucose levels more than the "only islet" transplanted group (Fig. 5A). Furthermore, intraperitoneal blood glucose tolerance tests performed 28 days after transplantation revealed that "islets transplanted with PA gel" display a pattern similar to the healthy control group; however, this pattern was not observed in the sham group and "islet only" group (Fig. 5B).

Morphological analysis of the integrity of islets by hematoxylin and eosin staining showed that "islets with PA gel" group preserved their original shape, while the "only islet" group did not. Correlation between morphological integrity and functionality was previously shown and the morphological integrity of the transplanted islets might have contributed to better glucose responsiveness of the "islets with PA gel" group [54].

Insulin positive cells were identified by immunohistochemistry (IHC) in islet grafts transplanted both in the presence and the absence of the PA gel, suggesting that the islets were functional in vivo under both conditions. However, the number of insulinpositive cells was strikingly enhanced in the presence of the PA gel (Fig. 6G and H). This result supports the conclusion that preservation of islet integrity by the PA gel improves islet functionality (insulin production) in vivo.

In healthy individuals, islets of Langerhans are surrounded by a collagen matrix $[54,60]$. Collagen was deposited within implanted PA gels, as demonstrated by IHC, whether or not islets were present within the gel, but collagen deposition was not noted in sham-operated or islet-only controls. This biological activity, collagen deposition, might trigger the formation of an extracellular matrix for the islets similar to the natural microenvironment after transplantation and therefore could enhance transplantation efficiency (Fig. 6J and L). Relatively fewer macrophages were present around islets in the PA gel compared to the numbers of macrophages around islets alone, as demonstrated by IHC (Fig. S4). Reduced macrophage infiltration after surgery might prevent excess cell death, help to maintain islet integrity and functionality, retain the insulin secretory capacity, and lower blood glucose levels for a longer period. Implantation of the PA alone resulted in a more intense immune response (macrophage infiltration) than transplantation of islets in PA gel or transplantation of islets only. This might have resulted because the release of various cytokines from injured islets prevents macrophage recruitment to the transplantation site [61-65].

Anti-von Willebrand staining was used to demonstrate vascularization inside and around the islets, and in the omentum when PA gel was applied or not (Fig. 7B-D). After blood vessel counting and assessment for all animals in all groups, it was clarified that the PA gel also promotes vascularization in vivo (Fig. 7E). The significant difference between vessel numbers in islets without PA compared to with PA may have been caused by the ability of HM-PA to bind growth factors, concentrate them, and provide them in excess amounts as previously shown $[43,47]$. In islet transplantation, numbers of blood vessels in the transplantation site are an important issue. In order to increase transplantation efficiency, get a faster response to elevated glucose levels, and supply enough oxygen and nutrients to the islets, a sufficient number of blood vessels is required in the transplantation sides. Mammadov et al. previously showed that HM-PA enhances tube formation by endothelial cells in vitro compared to Matrigel ${ }^{\circledR}$ [47]. That provides an explanation for our in vivo vascularization result, comparing vessel numbers in the presence of the PA gel versus normal, nontransplanted controls, and sham groups. With the PA gel system, it was shown that vascularization in the omenta of animals can be increased; and when this system is used with islets in transplantation operation for T1D treatment, it increases the efficiency and stabilizes blood glucose levels more effectively compared to bare islet transplantation.

\section{Conclusion}

In order to increase the islet transplantation efficiency, it is important to maintain the required environment for survival and function of islets both in vitro and in vivo. Herein, we presented a bioactive peptide amphiphile nanofiber gel platform for islet culture and transplantation. Chemical and physiological characterization studies of PAs showed that they can be used as synthetic ECM mimicking agents with their nanofibrous structures. Our results demonstrated that the PA gel provided a potent environment, diffusion and mechanical support for viability and function of islets. Under the serum-free condition, PA gel with the support of the VEGF and FGF-2 provided GSI of fresh isolated islets even after the 7 days of culture. These findings indicated that the PA gel can be used for long-term culture of islets until the transplantation. Furthermore, in vivo results indicated that islets transplanted with PA scaffolds controlled blood glucose levels of STZ-induced 
diabetic rats more effectively than islets transplanted in the absence of the PA gel. This finding showed that a supportive and bioactive scaffold helps to increase transplantation efficiency.

Also, our histological analyses demonstrated that islets transplanted with the HM-PA gel were insulin positive for up to 28 days, and vessel numbers were increased in groups containing the HMPA gel. These results may be explained by the affinity of the supramolecule HM-PA for growth factors which are key elements of angiogenesis (VEGF and FGF2) and the ability of the HM-PA gel to deliver them locally at the transplant site.

\section{Acknowledgements}

We thank M. Guler, Z. Erdogan, Z. Soran, I. Ulusoy and G. Boyuk for helping with TEM, LC-MS, isolation and transplantation experiments, respectively. This work was supported by the Scientific and Technological Research Council of Turkey (TUBITAK) Grant Numbers 111 S010 and 112T042. M.O.G and A.B.T. acknowledge support from the Turkish Academy of Sciences Distinguished Young Scientist Award (TUBA-GEBIP).

\section{Appendix A. Figures with essential colour discrimination}

Certain figures in this article, particularly Figs. 1-7 are difficult to interpret in black and white. The full colour images can be found in the on-line version, at http://dx.doi.org/10.1016/j.actbio.2015. 04.032 .

\section{Appendix B. Supplementary data}

Supplementary data associated with this article can be found, in the online version, at http://dx.doi.org/10.1016/j.actbio.2015.04. 032.

\section{References}

[1] Olefsky JM. Prospects for research in diabetes mellitus. JAMA 2001;285:628-32.

[2] Kizilel S, Garfinkel M, Opara E. The bioartificial pancreas: progress and challenges. Diabetes Technol Ther 2005;7:968-85.

[3] Barrett-Connor E, Khaw KT. Diabetes mellitus: an independent risk factor for stroke? Am J Epidemiol 1988;128:116-23.

[4] Barrett-Connor E, Orchard TJ. Insulin-dependent diabetes mellitus and ischemic heart disease. Diabetes Care 1985;8(Suppl. 1):65-70.

[5] Bild DE, Selby JV, Sinnock P, Browner WS, Braveman P, Showstack JA. Lowerextremity amputation in people with diabetes. Epidemiol prevention. Diabetes Care 1989;12:24-31.

[6] Geiss LS, Herman WH, Teutsch SM. Diabetes and renal mortality in the United States. Am J Public Health 1985;75:1325-6.

[7] Moss SE, Klein R, Klein BE. The incidence of vision loss in a diabetic population. Ophthalmology 1988;95:1340-8.

[8] Nathan DM. Long-term complications of diabetes mellitus. N Engl J Med 1993;328:1676-85.

[9] LaPorte RE, Tajima N, Akerblom HK, Berlin N, Brosseau J, Christy M, et al. Geographic differences in the risk of insulin-dependent diabetes mellitus: the importance of registries. Diabetes Care 1985;8(Suppl. 1):101-7.

[10] Bloomgarden ZT. Diabetes complications. Diabetes Care 2004;27:1506-14.

[11] Narang AS, Mahato RI. Biological and biomaterial approaches for improved islet transplantation. Pharmacol Rev 2006;58:194-243.

[12] Harlan DM, Kenyon NS, Korsgren O, Roep BO. Current advances and travails in islet transplantation. Diabetes 2009;58:2175-84.

[13] Robertson RP. Islet transplantation as a treatment for diabetes - a work in progress. N Engl J Med 2004;350:694-705.

[14] Nanji SA, Shapiro AM. Advances in pancreatic islet transplantation in humans. Diabetes Obes Metab 2006;8:15-25.

[15] Paraskevas S, Maysinger D, Wang R, Duguid TP, Rosenberg L. Cell loss in isolated human islets occurs by apoptosis. Pancreas 2000;20:270-6.

[16] Menger MD, Vajkoczy P, Beger C, Messmer K. Orientation of microvascular blood flow in pancreatic islet isografts. J Clin Invest 1994;93:2280-5.

[17] Beger C, Cirulli V, Vajkoczy P, Halban PA, Menger MD. Vascularization of purified pancreatic islet-like cell aggregates (pseudoislets) after syngeneic transplantation. Diabetes 1998;47:559-65.
[18] Furuya H, Kimura T, Murakami M, Katayama K, Hirose K, Yamaguchi A. Revascularization and function of pancreatic islet isografts in diabetic rats following transplantation. Cell Transplant 2003;12:537-44.

[19] Merchant FA, Diller KR, Aggarwal SJ, Bovik AC. Angiogenesis in cultured and cryopreserved pancreatic islet grafts. Transplantation 1997;63:1652-60.

[20] Vajkoczy P, Menger MD, Simpson E, Messmer K. Angiogenesis and vascularization of murine pancreatic islet isografts. Transplantation 1995;60:123-7.

[21] Mattsson G. The endothelial cells in islets of langerhans. Ups J Med Sci 2005;110:1-15.

[22] Vasir B, Aiello LP, Yoon KH, Quickel RR, Bonner-Weir S, Weir GC. Hypoxia induces vascular endothelial growth factor gene and protein expression in cultured rat islet cells. Diabetes 1998;47:1894-903.

[23] Kemp CB, Knight MJ, Scharp DW, Lacy PE, Ballinger WF. Transplantation of isolated pancreatic islets into the portal vein of diabetic rats. Nature 1973;244:447.

[24] Carlsson PO, Palm F, Andersson A, Liss P. Markedly decreased oxygen tension in transplanted rat pancreatic islets irrespective of the implantation site. Diabetes 2001:50:489-95.

[25] Selawry HP, Whittington K. Extended allograft survival of islets grafted into intra-abdominally placed testis. Diabetes 1984;33:405-6.

[26] Perez V, Caicedo A, Berman D, Arrieta E, Abdulreda M, Rodriguez-Diaz R, et al The anterior chamber of the eye as a clinical transplantation site for the treatment of diabetes: a study in a baboon model of diabetes. Diabetologia 2011;54:1121-6.

[27] Kriz J, Vilk G, Mazzuca DM, Toleikis PM, Foster PJ, White DJ. A novel technique for the transplantation of pancreatic islets within a vascularized device into the greater omentum to achieve insulin independence. Am J Surg 2012;203:793-7.

[28] Asai S, Kamei Y, Torii S. One-stage reconstruction of infected cranial defects using a titanium mesh plate enclosed in an omental flap. Ann Plast Surg 2004;52:144-7.

[29] Vineberg AM. Revascularization of the entire heart by internal mammary artery implantation, epicardiectomy and free omental graft. Can Med Assoc J 1966;94:378-85.

[30] de la Torre JC, Goldsmith HS. Coerulospinal fiber regeneration in transected feline spinal cord. Brain Res Bull 1994;35:413-7.

[31] Merani S, Toso C, Emamaullee J, Shapiro AM. Optimal implantation site for pancreatic islet transplantation. Br J Surg 2008;95:1449-61.

[32] Thomas F, Wu J, Contreras JL, Smyth C, Bilbao G, He J, et al. A tripartite anoikislike mechanism causes early isolated islet apoptosis. Surgery 2001;130:333-8.

[33] Lucas-Clerc C, Massart C, Campion JP, Launois B, Nicol M. Long-term culture of human pancreatic islets in an extracellular matrix: morphological and metabolic effects. Mol Cell Endocrinol 1993;94:9-20.

[34] Wang RN, Rosenberg L. Maintenance of beta-cell function and survival following islet isolation requires re-establishment of the islet-matrix relationship. J Endocrinol 1999;163:181-90.

[35] Beattie GM, Montgomery AM, Lopez AD, Hao E, Perez B, Just ML, et al. A novel approach to increase human islet cell mass while preserving beta-cell function. Diabetes 2002;51:3435-9.

[36] Jiang HZ, Guler MO, Stupp SI. The internal structure of self-assembled peptide amphiphiles nanofibers. Soft Matter 2007;3:454-62.

[37] Stendahl JC, Rao MS, Guler MO, Stupp SI. Intermolecular forces in the selfassembly of peptide amphiphile nanofibers. Adv Funct Mater 2006;16:499-508.

[38] Mata A, Geng Y, Henrikson KJ, Aparicio C, Stock SR, Satcher RL, et al. Bone regeneration mediated by biomimetic mineralization of a nanofiber matrix. Biomaterials 2010;31:6004-12.

[39] Murphy MB, Blashki D, Buchanan RM, Fan D, De Rosa E, Shah RN, et al. Multicomposite bioactive osteogenic sponges featuring mesenchymal stem cells, platelet-rich plasma, nanoporous silicon enclosures, and Peptide amphiphiles for rapid bone regeneration. J Funct Biomater 2011;2:39-66.

[40] Mammadov B, Mammadov R, Guler MO, Tekinay AB. Cooperative effect of heparan sulfate and laminin mimetic peptide nanofibers on the promotion of neurite outgrowth. Acta Biomater 2012;8:2077-86.

[41] Uzunalli G, Soran Z, Erkal TS, Dagdas YS, Dinc E, Hondur AM, et al. Bioactive self-assembled peptide nanofibers for corneal stroma regeneration. Acta Biomater 2014;10:1156-66.

[42] Cui H, Webber MJ, Stupp SI. Self-assembly of peptide amphiphiles: from molecules to nanostructures to biomaterials. Pept Sci 2010;94:1-18.

[43] Mammadov R, Mammadov B, Toksoz S, Aydin B, Yagci R, Tekinay AB, et al. Heparin mimetic peptide nanofibers promote angiogenesis. Biomacromolecules 2011;12:3508-19.

[44] Dagli Gul AS, Fadillioglu E, Karabulut I, Yesilyurt A, Delibasi T. The effects of oral carvacrol treatment against $\mathrm{H}_{2} \mathrm{O}_{2}$ induced injury on isolated pancreas islet cells of rats. Islets 2013;5:149-55.

[45] Morgan NG, Diakogiannaki E, Russell MA. The incubation and monitoring of cell viability in primary rat islets of Langerhans and pancreatic beta-cell lines. Methods Mol Biol 2009;560:53-64.

[46] Carter JD, Dula SB, Corbin KL, Wu R, Nunemaker CS. A practical guide to rodent islet isolation and assessment. Biol Proced Online 2009;11:3-31.

[47] Mammadov R, Mammadov B, Guler MO, Tekinay AB. Growth factor binding on heparin mimetic peptide nanofibers. Biomacromolecules 2012;13: 3311-9.

[48] Zheng X, Baker H, Hancock WS, Fawaz F, McCaman M, Pungor Jr E. Proteomic analysis for the assessment of different lots of fetal bovine serum as a raw 
material for cell culture. Part IV. Application of proteomics to the manufacture of biological drugs. Biotechnol Prog 2006;22:1294-300.

[49] Daoud J, Rosenberg L, Tabrizian M. Pancreatic islet culture and preservation strategies: advances, challenges, and future outlook. Cell Transplant 2010;19:1523-35.

[50] Ayala JE, Samuel VT, Morton GJ, Obici S, Croniger CM, Shulman GI, et al. Standard operating procedures for describing and performing metabolic tests of glucose homeostasis in mice. Dis Models Mech 2010;3:525-34.

[51] Rak J, Weitz JI. Heparin and angiogenesis: size matters! Arterioscler Thromb Vasc Biol 2003;23:1954-5.

[52] Niece KL, Hartgerink JD, Donners JJ, Stupp SI. Self-assembly combining two bioactive peptide-amphiphile molecules into nanofibers by electrostatic attraction. J Am Chem Soc 2003;125:7146-7.

[53] Greenfield N, Fasman GD. Computed circular dichroism spectra for the evaluation of protein conformation. Biochemistry 1969;8:4108-16.

[54] Stendahl JC, Kaufman DB, Stupp SI. Extracellular matrix in pancreatic islets: relevance to scaffold design and transplantation. Cell Transplant 2009; $18: 1-12$.

[55] Ilieva A, Yuan S, Wang RN, Agapitos D, Hill DJ, Rosenberg L. Pancreatic islet cell survival following islet isolation: the role of cellular interactions in the pancreas. J Endocrinol 1999;161:357-64.

[56] Gelain F, Bottai D, Vescovi A, Zhang S. Designer self-assembling peptide nanofiber scaffolds for adult mouse neural stem cell 3-dimensional cultures. PLoS ONE 2006;1:e119.

[57] Knepper PA, Mayanil CS, Goossens W, McLone DC, Hayes E. The presence of transcription factors in fetal bovine sera. In Vitro Cell Dev Biol Anim 1998;34:170-3.
[58] Bennet W, Sundberg B, Lundgren T, Tibell A, Groth CG, Richards A, et al. Damage to porcine islets of langerhans after exposure to human blood in vitro, or after intraportal transplantation to cynomologus monkeys - protective effects of sCR1 and heparin. Transplantation 2000;69:711-9.

[59] Shah S, Lowery E, Braun RK, Martin A, Huang N, Medina M, et al. Cellular basis of tissue regeneration by omentum. PLoS One 2012;7.

[60] Daoud J, Petropavlovskaia M, Rosenberg L, Tabrizian M. The effect of extracellular matrix components on the preservation of human islet function in vitro. Biomaterials 2010;31:1676-82.

[61] Chen T, Yuan J, Duncanson S, Hibert ML, Kodish BC, Mylavaganam G, et al. Alginate encapsulant incorporating CXCL12 Supports long-term Allo- and Xenoislet transplantation without systemic immune suppression. Am J Transpl 2015;15:618-27.

[62] Lang R, Rutschman RL, Greaves DR, Murray PJ. Autocrine deactivation of macrophages in transgenic mice constitutively overexpressing IL-10 under control of the human CD68 promoter. J Immunol 2002;168:3402-11.

[63] Meiron M, Zohar Y, Anunu R, Wildbaum G, Karin N. CXCL12 (SDF-1alpha) suppresses ongoing experimental autoimmune encephalomyelitis by selecting antigen-specific regulatory T cells. J Exp Med 2008;205:2643-55.

[64] Yano T, Liu Z, Donovan J, Thomas MK, Habener JF. Stromal cell derived factor-1 (SDF-1)/CXCL12 attenuates diabetes in mice and promotes pancreatic betacell survival by activation of the prosurvival kinase Akt. Diabetes 2007:56:2946-57.

[65] Liu Z, Stanojevic V, Avadhani S, Yano T, Habener JF. Stromal cell-derived factor1 (SDF-1)/chemokine (C-X-C motif) receptor 4 (CXCR4) axis activation induces intra-islet glucagon-like peptide-1 (GLP-1) production and enhances beta cell survival. Diabetologia 2011;54:2067-76. 